\title{
XXXII. Further remarks on Mr. Aitken's Theory of Dew
}

\section{Charles Tomlinson F.R.S.}

To cite this article: Charles Tomlinson F.R.S. (1886) XXXII. Further remarks on Mr. Aitken's Theory of Dew, Philosophical Magazine Series 5, 22:136, 270-272, DOI: 10.1080/14786448608627930

To link to this article: http://dx.doi.org/10.1080/14786448608627930

曲 Published online: 29 Apr 2009.

Submit your article to this journal $\sqsubset \pi$

Џ Article views: 2

Q View related articles $\sqsubset$ 
numerical measure of either being $\frac{1}{2} \mathrm{E} r$. Thus, according to the theory first mentioned, in the case of torsion of a composite circular bar, if the couple of torsion be such that $\frac{1}{2} \mathbf{E}$ r exceed at any distance from the axis the limit of safety, as determined by tractional experiments, for the material at that distance rupture will ensue. The rupture would at first be limited to the single material ; and if it proceeded right round would merely produce an increased strain in the remaining media, which might or might not, according to circumstances, produce further rupture. In practice, rupture would in all probability be at first limited to a small region, and the bar would undoubtedly tend to become warped. Direct experiments on the rupture of isotropic bars by torsion may disprove the above theory, but it is fairly obvious that the true law must depend on the state of strain and stress in the material. Thus the preceding solution will in any case supply the data that may be necessary in determining the limit of safety of a composite bar under torsion.

XXXII. Further Remarks on Mr. Aitken's Theory of Dew. By Charles Tomlinson,:"F.R.S.**

I HAD no idea that the innocent title of my paper, "Remarks on a New Theory of Dew," had a guilty meaning ; but according to Mr. Aitken I " was raising a false contention," and so attempting to place the author "in opposition to recognized authorities"; that the results of his investigation "are in no sense entitled to be called new ;" and he repeatedly states that his investigation was not promulgated in opposition to the theory of Dr. Wells, but "in extension of the work, the foundations of which were laid by Dr. Wells." Again, he says the new theory "is not in opposition, nor are the results contrary to the teaching of Dr. Wells." Once more, the author " never made any attempt to set aside Wells's theory."

And yet it is curious to notice that 'Chambers's Journal' for May ,29th last contains an article headed " A New Theory of Dew," in which the writer, after giving an accurate outline of Wells's theory, goes on to say that Mr. Aitken " has brought forward many observations, and the results of numerous experiments, which appear to prove that Dr. Wells' theory of dew is not, after all, correct." We are further informed that

* Communicated by the Author. 
" the essential difference between the old and the new theories is as to the source of the moisture which forms the dew. Instead of being condensed from the air above by the cool vegetation, Mr. Aitken maintains that it comes from the ground."

Again the Chambers's article, referring to Wells, says :"The points of the grass, small twigs, and all other good radiating surfaces are cooled the most; and accordingly we find the dew-drops most abundant on these bodies ; whilst on metal, or hard stone surfaces, which are poor radiators, we seldom or never find any dew." This is the Wells picture ; the writer now turns to the Aitken picture. "A closer observation reveals the fact that these so-called 'dewdrops' are formed at the end of the minute veins of the leaves and grass, and are not now recognised as dew at all, but moisture exuded from the interior of the plants themselves."

And yet Mr. Aitken is angry with me for calling his theory new, and for asserting that, if true, it will supersede the labours of previous observers. He says :- "I do not find that he [Mr. Tomlinson] adduces any results of previous observers that are in any way rendered nugatory by the results set forth in my paper."

If Mr. Aitken would condescend to study the classical memoir of Melloni (an abstract of which occupies the greater part of my paper), I should be much surprised if he did not become a convert to its experimental methods and conclusions. But at present he sees through the spectacles of his own theory, and therefore cannot appreciate the force of Melloni's singular care with which he protected his thermometers from sharing in the radiation of the surrounding bodies, whose temperature they had to indicate; for while other observers get differences of temperature between their two thermometers, amounting in some cases to as much as $16^{\circ}$ or $18^{\circ} \mathrm{F}$., Melloni is satisfied with a difference of only $2^{\circ}$ or $3^{\circ} \mathrm{C}$., and his theory of convection justifies this modest difference, and also accounts for many other phenomena, including the inverted trays and other objects which Mr. Aitken found wetted only on their under surfaces.

In like manner Mr. Aitken does not see the force of the observations made in Persia and the African Desert, seeing that his remarks "apply only to this climate." Surely the great forces of Nature rule as impartially in Persia and in Africa as in Scotland; and where no aerial vapour exists, there is no deposit of dew. The cases given were intended to show that in the arid regions there was no dew ; but that long 
before the travellers reached any considerable body of water, nocturnal dews were abundant, and they were deposited from the air, and did not rise out of the ground.

$\mathrm{Mr}$. Aitken also remarks that my notice of the Florentine Academicians, of Robert Boyle, and Le Roi have no bearing on the subject. The bearing is that these early observers proved that the moisture which forms dew and hoar frost exists in the air, and does not exhale from the ground.

$\mathrm{Mr}$. Aitken is also "puzzled to understand" what bearing Pictet's observation has on the subject. In the abstract in 'Nature' of Mr. Aitken's memoir, it appears as an original discovery that " these observations made at night showed the ground at a short distance below the surface to be always hotter than the air over it." Pictet observed the same fact in 1779. So also in my account of the weighed turf, I certainly did not wilfully form a " misconception of the essential features of the experiment," when I compared it to objects which, when exposed on Patrick Wilson's scale-board, gained weight, while in Mr. Aitken's case the turf lost weight. It is true that my observations were founded on the abstract of the memoir contained in 'Nature.' In January last I wrote for a copy of the memoir, which was promised as soon as the 'Edinburgh Transactions' were published. I waited until May and did not receive it. I inquired for it at the Royal Society in June, but it had not arrived, nor have I yet had the privilege of reading it. Mr. Aitken is therefore entitled to any advantage that may arise from my use of the abstract instead of the original memoir.

As I do not intend to write again on this subject, I conclude by assuring Mr. Aitken that I have no unfriendly feeling towards him ; but on the contrary freely admit that he has achieved much good scientific work, which I cannot but admire ; but as regards his new theory of Dew I think ho has gone astray, and in the interests of scientific truth I have ventured to criticise it. The subject is one that has occupied a great deal of my attention, and there is no doubt in my mind that, if this theory be accepted, a large amount of excellent work on the part of first-rate observers must be set aside as false.

Highgate, N., August 9, 1886. 